\title{
An extreme point characterization of strategy-proof and unanimous probabilistic rules over binary restricted domains
}

\author{
Citation for published version (APA):
}

Peters, H. J. M., Roy, S., Sadhukhan, S., \& Storcken, A. J. A. (2016). An extreme point characterization of strategy-proof and unanimous probabilistic rules over binary restricted domains. Maastricht University, Graduate School of Business and Economics. GSBE Research Memoranda No. 012 https://doi.org/10.26481/umagsb.2016012

Document status and date:

Published: 01/01/2016

DOI:

10.26481/umagsb.2016012

Document Version:

Publisher's PDF, also known as Version of record

\section{Please check the document version of this publication:}

- A submitted manuscript is the version of the article upon submission and before peer-review. There can be important differences between the submitted version and the official published version of record. People interested in the research are advised to contact the author for the final version of the publication, or visit the DOI to the publisher's website.

- The final author version and the galley proof are versions of the publication after peer review.

- The final published version features the final layout of the paper including the volume, issue and page numbers.

Link to publication

\footnotetext{
General rights rights.

- You may freely distribute the URL identifying the publication in the public portal. please follow below link for the End User Agreement:

www.umlib.nl/taverne-license

Take down policy

If you believe that this document breaches copyright please contact us at:

repository@maastrichtuniversity.nl

providing details and we will investigate your claim.
}

Copyright and moral rights for the publications made accessible in the public portal are retained by the authors and/or other copyright owners and it is a condition of accessing publications that users recognise and abide by the legal requirements associated with these

- Users may download and print one copy of any publication from the public portal for the purpose of private study or research.

- You may not further distribute the material or use it for any profit-making activity or commercial gain

If the publication is distributed under the terms of Article $25 \mathrm{fa}$ of the Dutch Copyright Act, indicated by the "Taverne" license above, 
Hans Peters, Souvik Roy, Soumyarup Sadhukhan, Ton Storcken

An Extreme Point

Characterization of Strategyproof and Unanimous Probabilistic Rules over Binary Restricted Domains

RM/16/012

\section{GSBE}

Maastricht University School of Business and Economics

Graduate School of Business and Economics

\section{P.O Box 616}

NL- 6200 MD Maastricht

The Netherlands 


\title{
An Extreme Point Characterization of Strategy-PRoof and Unanimous Probabilistic Rules over Binary Restricted Domains*
}

\author{
Hans Peters $^{\dagger} \quad$ Souvik Roy Soumyarup Sadhukhan $^{\ddagger} \quad$ Ton Storcken \\ This version, February 2016
}

\begin{abstract}
We show that every strategy-proof and unanimous probabilistic rule on a binary restricted domain has binary support, and is a probabilistic mixture of strategy-proof and unanimous deterministic rules. Examples of binary restricted domains include several types of single-dipped domains, the single-peaked domain where peaks are restricted to two adjacent alternatives, and the single-crossing domain with two tops. We also provide some extensions to infinitely many alternatives.
\end{abstract}

Keywords Strategy-proofness, probabilistic rules, binary restricted domains JEL-codes D71

\section{Introduction}

Suppose that in choosing between red and white wine, half of the dinner party is in favor of red wine while the other half prefers white wine. In this situation a deterministic rule has to choose one of the two alternatives, where a fifty-fifty lottery seems to be more fair. In general, for every preference profile a probabilistic rule selects a lottery over the set of alternatives. Gibbard (1977) provides a characterization of all strategy-proof probabilistic rules over the complete domain of preferences (see also Sen, 2011). In particular, if in addition a rule is unanimous, then it is a probability mixture of deterministic rules. This result implies that in order to analyze probabilistic rules it is sufficient to study deterministic rules only.

In Peters et al (2014) it is shown that if preferences are single-peaked over a finite set of alternatives then every strategy-proof and unanimous probabilistic rule is a mixture of strategy-proof and unanimous deterministic rules. The same is true for the multi-dimensional domain with lexicographic preferences (Chatterji et al, 2012). But it is not necessarily true for all dictatorial domains (Chatterji et al 2014), in particular, there are domains where all strategy-proof and unanimous

*The authors would like to thank Arunava Sen and Gopakumar Achuthankutty for their invaluable suggestions.

${ }^{\dagger}$ Department of Quantitative Economics, Maastricht University. Email: h.peters@maastrichtuniversity.nl

${ }^{\ddagger}$ Economic Research Unit, Indian Statistical Institute, Kolkata, and Department of Quantitative Economics, Maastricht University. Email: souvik2004@gmail.com

$\S$ Economic Research Unit, Indian Statistical Institute, Kolkata. Email:

『Department of Quantitative Economics, Maastricht University. Email: t.storcken@maastrichtuniversity.nl 
deterministic rules are dictatorial but not all strategy-proof and unanimous probabilistic rules are random dictatorships.

A binary restricted domain over two alternatives $x$ and $y$ is a domain of preferences where the top alternative(s) of each preference belong(s) to the set $\{x, y\}$ (we allow for indifferences); and moreover, for every preference with top $x$ there is a preference with top $y$ such that the only alternatives weakly preferred to $y$ in the former and $x$ in the latter preference, are $x$ and $y$. Outstanding examples are: domains of single-dipped preferences on an interval $[x, y]$; domains with single-peaked preferences with only two possible and adjacent top alternatives; and single-crossing domains with only two possible top alternatives.

Peremans and Storcken (1999) have shown the equivalence between individual and group strategy proofness in subdomains of single-dipped preferences. They characterize a general class of strategy-proof deterministic rules.

In Manjunath (2014) the problem of locating a single public bad along a segment when agents' preferences are single-dipped is studied. In particular, all strategy-proof and unanimous deterministic rules are characterized.

In Barberà et al (2012) it is shown that, when all single-dipped preferences are admissible, the range of a strategy-proof and unanimous deterministic rule contains at most two alternatives. The paper also provides examples of sub-domains admitting strategy-proof rules with larger ranges.

In the present paper we show that every strategy-proof and unanimous probabilistic rule over a binary restricted domain over $x$ and $y$ has binary support, i.e., for every preference profile probability 1 is assigned to $\{x, y\}$. We also show that if a strategy-proof and unanimous probabilistic rule has binary support then it can be written as a convex combination of deterministic social choice rules. Moreover, we present a complete characterization of such rules, namely as generalized voting by committee rules.

The paper is organized as follows. The next section introduces the model and definitions. Section 3 contains the main results, Section 4 contains examples of domains to which our results apply, and Section 5 presents an extension to the case where the number of alternatives may be infinite. Section 6 concludes.

\section{Preliminaries}

Let $A$ be a finite set of at least two alternatives and let $N=\{1, \ldots, n\}$ be a finite set of at least two agents. Let $\mathbb{W}(A)$ be the set of (weak) preferences over $A{ }^{1}$ By $P$ and $I$ we denote the asymmetric and symmetric parts of $R \in \mathbb{W}(A)$. For $R \in \mathbb{W}(A)$ by $\tau(R)$ we denote the first ranked alternative(s) in $R$, defined as $\tau(R)=\{x \in A: x R y$ for all $y \in A\}$. In general, the notation $\mathcal{D}$ will be used for a set of admissible weak preferences for an agent $i \in N$. As is clear from the notation, we assume the same set of admissible preferences for every agent. A preference profile, denoted by $R_{N}=\left(R_{1}, R_{2}, \ldots, R_{n}\right)$, is an element of $\mathcal{D}^{n}=\mathcal{D} \times \mathcal{D} \times \ldots \times \mathcal{D}$. For notational convenience we often do not use brackets to denote singleton sets, e.g., we often denote a set $\{i\}$ by $i$.

Definition 2.1. A deterministic social choice function (DSCF) is a function $f: \mathcal{D}^{n} \rightarrow A$.

Definition 2.2. A DSCF $f$ is unanimous if $f\left(R_{N}\right) \in \cap_{i=1}^{n} \tau\left(R_{i}\right)$ for all $R_{N} \in \mathcal{D}^{n}$ such that $\cap_{i=1}^{n} \tau\left(R_{i}\right) \neq \emptyset$.

Agent $i \in N$ manipulates DSCF $f$ at $R_{N} \in \mathcal{D}^{n}$ via $R_{i}^{\prime}$ if $f\left(R_{i}^{\prime}, R_{-i}\right) P_{i} f\left(R_{N}\right)$.

\footnotetext{
${ }^{1}$ I.e., for all $R \in \mathbb{W}(A)$ and $x, y, z \in A$, we have $x R y$ or $y R x$ (completeness), and $x R y$ and $y R z$ imply $x R z$ (transitivity). Note that reflexivity $(x R x$ for all $x \in A)$ is implied.
} 
Definition 2.3. A DSCF $f$ is strategy-proof if for all $i \in N, R_{N} \in \mathcal{D}^{n}$, and $R_{i}^{\prime} \in \mathcal{D}, i$ does not manipulate $f$ at $R_{N}$ via $R_{i}^{\prime}$.

Definition 2.4. A probabilistic social choice function (PSCF) is a function $\Phi: \mathcal{D}^{n} \rightarrow \triangle A$ where $\triangle A$ is the set of probability distributions over $A$. A strict PSCF is a PSCF that is not a DSCF.

Observe that a deterministic social choice function can be identified with a probabilistic social choice function by assigning probability 1 to the chosen alternative.

For $a \in A$ and $R_{N} \in \mathcal{D}^{n}, \Phi_{a}\left(R_{N}\right)$ denotes the probability assigned to $a$ by $\Phi\left(R_{N}\right)$. For $S \subseteq A$, we denote $\Phi_{S}(R)=\sum_{a \in S} \Phi_{a}(R)$.

Definition 2.5. A PSCF $\Phi$ is unanimous if $\Phi_{\cap_{i=1}^{n} \tau\left(R_{i}\right)}\left(R_{N}\right)=1$ for all $R_{N} \in \mathcal{D}^{n}$ such that $\cap_{i=1}^{n} \tau\left(R_{i}\right) \neq \emptyset$.

Definition 2.6. For $R \in \mathcal{D}$ and $x \in A$, the upper contour set of $x$ at $R$ is the set $U(x, R)=\{y \in$ $X: y R x\}$. In particular, $x \in U(x, R)$.

Agent $i \in N$ manipulates $\operatorname{PSCF} \Phi$ at $R_{N} \in \mathcal{D}^{n}$ via $R_{i}^{\prime}$ if $\Phi_{U\left(x, R_{i}\right)}\left(R_{i}^{\prime}, R_{-i}\right)>\Phi_{U\left(x, R_{i}\right)}\left(R_{i}^{\prime}, R_{-i}\right)$ for some $x \in A$.

Definition 2.7. A PSCF $\Phi$ is strategy-proof if for all $i \in N, R_{N} \in \mathcal{D}^{n}$, and $R_{i}^{\prime} \in \mathcal{D}, i$ does not manipulate $\Phi$ at $R_{N}$ via $R_{i}^{\prime}$.

In other words, strategy-proofness of a PSCF means that a deviation results in a (first order) stochastically dominated lottery for the deviating agent.

For PSCFs $\Phi_{j}, j=1, \ldots, k$ and nonnegative numbers $\lambda_{j}, j=1, \ldots, k$, summing to 1 , we define the PSCF $\Phi=\sum_{j=1}^{k} \Phi_{j}$ by $\Phi_{x}\left(R_{N}\right)=\sum_{j=1}^{k} \Phi_{x}\left(R_{N}\right)$ for all $R_{N} \in \mathcal{D}^{n}$ and $x \in A$. We call $\Phi$ a convex combination of the PSCFs $\Phi_{j}$.

Definition 2.8. A domain $\mathcal{D}$ is said to be a deterministic extreme point domain if every strategyproof and unanimous PSCF on $\mathcal{D}^{n}$ can be written as a convex combination of strategy-proof and unanimous DSCFs on $\mathcal{D}^{n}$.

For $a \in A$, let $\mathcal{D}^{a}=\{R \in \mathcal{D}: \tau(R)=a\}$.

Definition 2.9. Let $x, y \in A, x \neq y$. A domain $\mathcal{D}$ is a binary restricted domain over $\{x, y\}$ if

(i) for all $R \in \mathcal{D}, \tau(R) \in\{\{x\},\{y\},\{x, y\}\}$,

(ii) for all $a, b \in\{x, y\}$ with $a \neq b$, and for each $R \in \mathcal{D}^{a}$, there exists $R^{\prime} \in \mathcal{D}^{b}$ such that $U(b, R) \cap U\left(a, R^{\prime}\right)=\{a, b\}$.

Definition 2.10. Let $x, y \in A, x \neq y$. A domain $\mathcal{D}$ is a binary support domain over $\{x, y\}$ if $\Phi_{\{x, y\}}\left(R_{N}\right)=1$ for every $R_{N} \in \mathcal{D}^{n}$ and every strategy-proof and unanimous PSCF $\Phi$ on $\mathcal{D}^{n} .^{2}$

\section{$3 \quad$ Results}

In this section we present the main results of this paper. First we show that every binary support domain is a deterministic extreme point domain (Corollary 3.1). Next we show that every binary restricted domain is a binary support domain (Theorem 3.3). Consequently, every binary restricted domain is a deterministic extreme point domain (Corollary 3.2). Next, we characterize the set of all strategy-proof and unanimous rules on such binary restricted domains. Finally, we provide a condition, more precisely a slight weakening of binary restrictedness, which is necessary for a domain to have binary support.

\footnotetext{
${ }^{2}$ It is not difficult to see that such a PSCF always exists.
} 


\subsection{Binary support domains are deterministic extreme point domains}

First we establish a necessary and sufficient condition for a domain to be a deterministic extreme point domain.

Theorem 3.1. A domain $\mathcal{D}$ is a deterministic extreme point domain if and only if every strategyproof and unanimous strict PSCF on $\mathcal{D}^{n}$ is a convex combination of two other distinct strategy-proof and unanimous PSCFs.

Proof. First, let $\mathcal{D}$ be an arbitrary domain. Observe that every PSCF $\Phi$ can be identified with a vector in $\mathbb{R}^{p m}$, where $p$ is the number of different preference profiles, i.e., the number of elements of $\mathcal{D}^{n}$, and $m$ is the number of elements of $A$. Compactness and convexity of a set of PSCFs are equivalent to convexity and compactness of the associated subset of $\mathbb{R}^{p m}$.

We show that the set of all strategy-proof and unanimous probabilistic rules $\mathcal{S}$ over $\mathcal{D}^{n}$ is compact and convex.

For convexity, let $\Phi^{\prime}, \Phi^{\prime \prime} \in \mathcal{S}$ and $0 \leq \alpha \leq 1$, and let the PSCF $\Phi$ be defined by $\Phi\left(R_{N}\right)=$ $\alpha \Phi^{\prime}\left(R_{N}\right)+(1-\alpha) \Phi^{\prime \prime}\left(R_{N}\right)$ for all $R_{N} \in \mathcal{D}^{n}$. Clearly, $\Phi$ is unanimous. For strategy-proofness, let $i \in N, R_{N} \in \mathcal{D}^{n}$ and $R_{i}^{\prime} \in \mathcal{D}$. Then by strategy-proofness of $\Phi^{\prime}$ and $\Phi^{\prime \prime}$ we have $\Phi_{U\left(b, R_{i}\right)}^{\prime}\left(R_{i}^{\prime}, R_{-i}\right) \leq$ $\Phi_{U\left(b, R_{i}\right)}\left(R_{N}\right)$ and $\Phi_{U\left(b, R_{i}\right)}^{\prime \prime}\left(R_{i}^{\prime}, R_{-i}\right) \leq \Phi_{U\left(b, R_{i}\right)}^{\prime \prime}\left(R_{N}\right)$, so that

$$
\alpha \Phi_{U\left(b, R_{i}\right)}^{\prime}\left(R_{i}^{\prime}, R_{-i}\right)+(1-\alpha) \Phi_{U\left(b, R_{i}\right)}^{\prime \prime}\left(R_{i}^{\prime}, R_{-i}\right) \leq \alpha \Phi_{U\left(b, R_{i}\right)}^{\prime}\left(R_{N}\right)+(1-\alpha) \Phi_{U\left(b, R_{i}\right)}^{\prime \prime}\left(R_{N}\right),
$$

hence $\Phi_{U\left(b, R_{i}\right)}\left(R_{i}^{\prime}, R_{-i}\right) \leq \Phi_{U\left(b, R_{i}\right)}\left(R_{N}\right)$. Thus, $\Phi$ is strategy-proof, and $\mathcal{S}$ is convex.

For closedness, consider a sequence $\Phi^{k}, k \in \mathbb{N}$, in $\mathcal{S}$ such that $\lim _{k \rightarrow \infty} \Phi^{k}=\Phi$, i.e., for all $x \in A$ and $R_{N} \in \mathcal{D}^{n}, \lim _{k \rightarrow \infty} \Phi_{x}^{k}\left(R_{N}\right)=\Phi_{x}\left(R_{N}\right)$. It is easy to see that $\Phi$ is unanimous. Suppose that $\Phi$ were not strategy-proof. Then there exist $i \in N, R_{N} \in \mathcal{D}^{n}$ and $R_{i}^{\prime} \in \mathcal{D}$ such that for some $b \in A$, $\Phi_{U\left(b, R_{i}\right)}\left(R_{i}^{\prime}, R_{-i}\right)>\Phi_{U\left(b, R_{i}\right)}\left(R_{N}\right)$. This means there exists $k \in \mathbb{N}$ such that $\Phi_{U\left(b, R_{i}\right)}^{k}\left(R_{i}^{\prime}, R_{-i}\right)>$ $\Phi_{U\left(b, R_{i}\right)}^{k}\left(R_{N}\right)$. This contradicts strategy-proofness of $\Phi^{k}$. So, $\mathcal{S}$ is closed. Clearly, $\mathcal{S}$ is bounded. Thus, it is compact.

Since $\mathcal{S}$ is compact and convex, by the Theorem of Krein-Milman (e.g., Rockafellar, 1970) it is the convex hull of its (non-empty set of) extreme points. Now, for the if-part of the theorem, for a domain $\mathcal{D}$ satisfying the premise, no strict PSCF is an extreme point. Thus, $\mathcal{D}$ is a deterministic extreme point domain. In fact, it is also easy to see that every strategy-proof and unanimous deterministic rule is an extreme point of $\mathcal{S}$.

For the only-if part, let $\mathcal{D}$ be a deterministic extreme point domain and let $\Phi$ be a strategy-proof and unanimous strict PSCF on $\mathcal{D}^{n}$. Then there are $\lambda_{1}, \ldots, \lambda_{k}, k \geq 2$, with $\lambda_{i}>0$ for all $i=1, \ldots, k$ and $\sum_{i=1}^{k} \lambda_{i}=1$, and strategy-proof and unanimous DSCFs $f_{1}, \ldots, f_{k}$ on $\mathcal{D}^{n}$ with $f_{i} \neq f_{j}$ for $i \neq j$, such that $\Phi=\sum_{i=1}^{k} \lambda_{i} f_{i}$. We define $\Phi^{\prime}=\sum_{i=2}^{k} \frac{\lambda_{i}}{1-\lambda_{1}} f_{i}$. Then $\Phi=\left(1-\lambda_{1}\right) \Phi^{\prime}+\lambda_{1} f_{1}$, and $\Phi^{\prime}$ and $f_{1}$ are distinct strategy-proof and unanimous PSCFs different from $\Phi$.

In the following theorem we show that if a strategy-proof and unanimous strict PSCF has binary support, then it can be written as a convex combination of two other strategy-proof and unanimous PSCFs.

Theorem 3.2. Let $\Phi: \mathcal{D}^{n} \rightarrow A$ be a strategy-proof and unanimous strict PSCF and let $x, y \in A$ such that $\Phi_{\{x, y\}}\left(R_{N}\right)=1$ for all $R_{N} \in \mathcal{D}^{n}$. Then there exist strategy-proof and unanimous PSCFs $\Phi^{\prime}, \Phi^{\prime \prime}$ with $\Phi^{\prime} \neq \Phi^{\prime \prime}$ such that $\Phi\left(R_{N}\right)=\frac{1}{2} \Phi^{\prime}\left(R_{N}\right)+\frac{1}{2} \Phi^{\prime \prime}\left(R_{N}\right)$ for all $R_{N} \in \mathcal{D}^{n}$. 
Proof. Note that $\Phi_{\{x, y\}}\left(R_{N}\right)=1$ for all $R_{N} \in \mathcal{D}^{n}$ implies that $\Phi\left(R_{N}\right)$ is completely determined by $\Phi_{x}\left(R_{N}\right)$ for all $R_{N} \in \mathcal{D}^{n}$. Since $\Phi$ is a strict PSCF, there exists $R_{N}^{\prime} \in \mathcal{D}^{n}$ such that $\Phi_{x}\left(R_{N}^{\prime}\right)=p \in$ $(0,1)$. Let $C=\left\{R_{N} \in \mathcal{D}^{n}: \Phi_{x}\left(R_{N}\right) \neq p\right\}$. Since $C$ is finite set, there is an $\epsilon \in(0, p)$ such that for all $R_{N} \in C, \Phi_{x}\left(R_{N}\right) \notin[p-\epsilon, p+\epsilon]$. We define $\Phi^{\prime}$ and $\Phi^{\prime \prime}$ with support $\{x, y\}$ by

$$
\Phi_{x}^{\prime}\left(R_{N}\right)=\left\{\begin{array}{l}
\Phi_{x}\left(R_{N}\right) \text { if } R_{N} \in C \\
\Phi_{x}\left(R_{N}\right)+\epsilon \text { otherwise }
\end{array} \quad \text { and } \Phi_{x}^{\prime \prime}\left(R_{N}\right)=\left\{\begin{array}{l}
\Phi_{x}\left(R_{N}\right) \text { if } R_{N} \in C \\
\Phi_{x}\left(R_{N}\right)-\epsilon \text { otherwise. }
\end{array}\right.\right.
$$

Clearly, $\Phi^{\prime} \neq \Phi^{\prime \prime}$ and $\Phi\left(R_{N}\right)=\frac{1}{2} \Phi^{\prime}\left(R_{N}\right)+\frac{1}{2} \Phi^{\prime \prime}\left(R_{N}\right)$ for all $R_{N} \in \mathcal{D}^{n}$. Unanimity of $\Phi^{\prime}$ and $\Phi^{\prime \prime}$ follows from unanimity of $\Phi$. We show that $\Phi^{\prime}$ and $\Phi^{\prime \prime}$ are strategy-proof. We consider only $\Phi^{\prime}$, the proof for $\Phi^{\prime \prime}$ is analogous. Let $i \in N, R_{N} \in \mathcal{D}^{n}$ and $Q_{i} \in \mathcal{D}$. Write $Q_{N}=\left(Q_{i}, R_{-i}\right)$. We consider the following cases.

Case $1 R_{N}, Q_{N} \notin C$. Then $\Phi_{x}^{\prime}\left(R_{N}\right)=p+\epsilon=\Phi_{x}\left(Q_{N}\right)$. So $i$ does not manipulate $\Phi^{\prime}$ at $R_{N}$.

Case $2 R_{N}, Q_{N} \in C$. Then $\Phi_{x}^{\prime}\left(R_{N}\right)=\Phi_{x}\left(R_{N}\right)$ and $\Phi_{x}^{\prime}\left(Q_{N}\right)=\Phi_{x}\left(Q_{N}\right)$. Since $i$ does not manipulate $\Phi$ at $R_{N}$ via $Q_{i}$, this implies that $i$ does not manipulate $\Phi^{\prime}$ at $R_{N}$ via $Q_{i}$.

Case $3 R_{N} \notin C, Q_{N} \in C$. If $x P_{i} y$ (where $P_{i}$ is the asymmetric part of $R_{i}$ ), then by strategyproofness of $\Phi, \Phi_{x}^{\prime}\left(Q_{N}\right)=\Phi_{x}\left(Q_{N}\right) \leq \Phi_{x}\left(R_{N}\right)=\Phi_{x}^{\prime}\left(R_{N}\right)-\epsilon<\Phi_{x}^{\prime}\left(R_{N}\right)$, so that $i$ does not manipulate $\Phi^{\prime}$ at $R^{N}$. If $y P_{i} x$, then by strategy-proofness of $\Phi$ and the choice of $\epsilon, \Phi_{x}^{\prime}\left(Q_{N}\right)=$ $\Phi_{x}\left(Q_{N}\right) \geq \Phi_{x}\left(R_{N}\right)+\epsilon=\Phi_{x}^{\prime}\left(R_{N}\right)$, so that $i$ does not manipulate $\Phi^{\prime}$ at $R_{N}$.

Case $4 R_{N} \in C, Q_{N} \notin C$. If $x P_{i} y$ then by strategy-proofness of $\Phi$ and the choice of $\epsilon, \Phi_{x}^{\prime}\left(Q_{N}\right)=$ $\Phi_{x}\left(Q_{N}\right)+\epsilon \leq\left(\Phi_{x}\left(R_{N}\right)-\epsilon\right)+\epsilon=\Phi_{x}\left(R_{N}\right)=\Phi_{x}^{\prime}\left(R_{N}\right)$, so that $i$ does not manipulate $\Phi^{\prime}$ at $R_{N}$. If $y P_{i} x$, then by strategy-proofness of $\Phi, \Phi_{y}^{\prime}\left(Q_{N}\right)=\Phi_{y}\left(Q_{N}\right)-\epsilon \leq \Phi_{y}\left(R_{N}\right)-\epsilon=\Phi_{y}^{\prime}\left(R_{N}\right)-\epsilon<\Phi_{y}^{\prime}\left(R_{N}\right)$, so that $i$ does not manipulate $\Phi^{\prime}$ at $R_{N}$.

Theorems 3.2 and 3.1 imply the following result.

Corollary 3.1. Every binary support domain is a deterministic extreme point domain.

\subsection{Binary restricted domains are binary support domains}

The main result of this subsection is the following theorem.

Theorem 3.3. Every binary restricted domain is a binary support domain.

We first prove the result for two agents and then use induction to prove it for an arbitrary number of agents.

Proposition 3.1. Let $\mathcal{D}$ be a binary restricted domain over $\{x, y\}$, and let $\Phi: \mathcal{D}^{2} \rightarrow \triangle A$ be a strategy-proof and unanimous PSCF. Then $\Phi_{\{x, y\}}(R)=1$ for all $R \in \mathcal{D}^{2}$.

Proof. By unanimity of $\Phi$ it is sufficient to consider the case where $R_{N}=\left(R_{1}, R_{2}\right)$ with $R_{1} \in \mathcal{D}^{x}$ and $R_{2} \in \mathcal{D}^{y}$.

First suppose that $U\left(y, R_{1}\right) \cap U\left(x, R_{2}\right)=\{x, y\}$. Assume for contradiction that $\Phi_{z}(R)>0$ for some $z \in A \backslash\{x, y\}$. If $z \notin U\left(y, R_{1}\right)$, then agent 1 manipulates at $R_{N}$ via some $R_{1}^{\prime} \in \mathcal{D}^{y}$, since by unanimity $\Phi_{y}\left(R_{1}^{\prime}, R_{2}\right)=1$ and $y$ is strictly preferred to $z$ at the preference $R_{1}$ of player 1 . So $z \in U\left(y, R_{1}\right)$. Similarly we have that $z \in U\left(x, R_{2}\right)$, contradicting $U\left(y, R_{1}\right) \cap U\left(x, R_{2}\right)=\{x, y\}$. Hence in this case $\Phi_{\{x, y\}}\left(R_{N}\right)=1$.

Next, suppose that $U\left(y, R_{1}\right) \cap U\left(x, R_{2}\right) \neq\{x, y\}$. This, by the definition of a binary restricted domain, means that there exist $R_{1}^{\prime}$ and $R_{2}^{\prime}$ such that $U\left(y, R_{1}\right) \cap U\left(x, R_{2}^{\prime}\right)=\{x, y\}$ and $U\left(y, R_{1}^{\prime}\right) \cap$ $U\left(x, R_{2}\right)=\{x, y\}$. By the first part of the proof we have $\Phi_{\{x, y\}}\left(R_{1}, R_{2}^{\prime}\right)=1$ and $\Phi_{\{x, y\}}\left(R_{1}^{\prime}, R_{2}\right)=$ 
1. Let $\Phi_{x}\left(R_{1}, R_{2}^{\prime}\right)=\epsilon$ and $\Phi_{x}\left(R_{1}^{\prime}, R_{2}\right)=\epsilon^{\prime}$. Since $R_{1}, R_{1}^{\prime} \in \mathcal{D}^{x}$ and $R_{2}, R_{2}^{\prime} \in \mathcal{D}^{y}$, strategyproofness implies $\Phi_{x}\left(R_{1}^{\prime}, R_{2}^{\prime}\right)=\Phi_{x}\left(R_{1}, R_{2}^{\prime}\right)=\epsilon$ and $\Phi_{y}\left(R_{1}^{\prime}, R_{2}^{\prime}\right)=\Phi_{y}\left(R_{1}^{\prime}, R_{2}\right)=1-\epsilon^{\prime}$. This means $\Phi_{\{x, y\}}\left(R_{1}^{\prime}, R_{2}^{\prime}\right)=\epsilon+1-\epsilon^{\prime}$, which implies $\epsilon \leq \epsilon^{\prime}$. By a similar argument it follows that $\epsilon^{\prime} \leq \epsilon$. Hence, $\epsilon=\epsilon^{\prime}$. Finally, again since $R_{1}, R_{1}^{\prime} \in \mathcal{D}^{x}$ and $R_{2}, R_{2}^{\prime} \in \mathcal{D}^{y}$, we have by strategy-proofness that $\Phi_{x}\left(R_{1}, R_{2}\right)=\Phi_{x}\left(R_{1}^{\prime}, R_{2}\right)=\epsilon$ and $\Phi_{y}\left(R_{1}, R_{2}\right)=\Phi_{y}\left(R_{1}, R_{2}^{\prime}\right)=1-\epsilon$, and hence $\Phi_{\{x, y\}}\left(R_{1}, R_{2}\right)=1$, completing the proof.

The following proposition treats the case with more than two agents.

Proposition 3.2. Let $n \geq 3$, let $\mathcal{D}$ be binary restricted domain over $\{x, y\}$, and let $\Phi: \mathcal{D}^{n} \rightarrow \triangle A$ be a strategy-proof and unanimous PSCF. Then $\Phi_{\{x, y\}}\left(R_{N}\right)=1$ for all $R_{N} \in \mathcal{D}^{n}$.

Proof. As before, $N=\{1, \ldots, n\}$ is the set of voters. We prove the result by induction. Assume that the proposition holds for all sets with $k<n$ voters.

Let $N^{*}=\{1,3,4, \ldots, n\}$ and define the PSCF $g: \mathcal{D}^{n-1} \rightarrow \triangle A$ for the set of voters $N^{*}$ as follows: For all $R_{N^{*}}=\left(R_{1}, R_{3}, \ldots, R_{n}\right) \in \mathcal{D}^{n-1}$,

$$
g\left(R_{1}, R_{3}, \ldots, R_{n}\right)=\Phi\left(R_{1}, R_{1}, R_{3}, R_{4}, \ldots, R_{n}\right) .
$$

Claim $1 g_{\{x, y\}}\left(R_{N^{*}}\right)=1$ for all $R_{N^{*}} \in \mathcal{D}^{n-1}$.

To prove this claim, first observe that $g$ inherits unanimity from $\Phi$. We show that $g$ also inherits strategy-proofness. It is easy to see that agents other than 1 do not manipulate $g$ since $\Phi$ is strategy-proof. Let $\left(R_{1}, R_{3}, \ldots, R_{n}\right) \in \mathcal{D}^{n-1}$ and $Q_{1} \in \mathcal{D}$. For all $b \in A$, we have

$$
\begin{aligned}
g_{U\left(b, R_{1}\right)}\left(R_{1}, R_{3}, \ldots, R_{n}\right) & =\Phi_{U\left(b, R_{1}\right)}\left(R_{1}, R_{1}, R_{3}, \ldots, R_{n}\right) \\
& \geq \Phi_{U\left(b, R_{1}\right)}\left(Q_{1}, R_{1}, R_{3}, \ldots, R_{n}\right) \\
& \geq \Phi_{U\left(b, R_{1}\right)}\left(Q_{1}, Q_{1}, R_{3}, \ldots, R_{n}\right) \\
& =g_{U\left(b, R_{1}\right)}\left(Q_{1}, R_{3}, \ldots, R_{n}\right)
\end{aligned}
$$

where the inequalities follow from strategy-proofness of $\Phi$. The proof of Claim 1 is now complete by the induction hypothesis. ${ }^{3}$

Thus, by Claim 1 , we have $\Phi_{\{x, y\}}\left(R_{N}\right)=1$ for all $R_{N} \in \mathcal{D}^{n}$ with $R_{1}=R_{2}$. Our next claim shows that the same holds if $\tau\left(R_{1}\right)=\tau\left(R_{2}\right)$.

Claim 2 Let $R_{N}$ be a preference profile such that $\tau\left(R_{1}\right)=\tau\left(R_{2}\right)$. Then $\Phi_{\{x, y\}}\left(R_{N}\right)=1$.

To prove this claim, first suppose that $\tau\left(R_{1}\right)=\tau\left(R_{2}\right)=\{x, y\}$. Then, if $\Phi_{\{x, y\}}\left(R_{N}\right)<1$, player 1 manipulates at $R_{N}$ via $R_{2}$ since by Claim $1, \Phi_{\{x, y\}}\left(R_{2}, R_{2}, R_{N \backslash\{1,2\}}\right)=1$. Now consider the case $\tau\left(R_{1}\right)=\tau\left(R_{2}\right) \in\{x, y\}$, say $\tau\left(R_{1}\right)=\tau\left(R_{2}\right)=x$. By Claim 1 we have $\Phi_{\{x, y\}}\left(R_{1}, R_{1}, R_{N \backslash\{1,2\}}\right)=$ $\Phi_{\{x, y\}}\left(R_{2}, R_{2}, R_{N \backslash\{1,2\}}\right)=1$. Moreover, since $\tau\left(R_{1}\right)=\tau\left(R_{2}\right)=x$ we have by strategy-proofness $\Phi_{x}\left(R_{1}, R_{1}, R_{N \backslash\{1,2\}}\right)=\Phi_{x}\left(R_{1}, R_{2}, R_{N \backslash\{1,2\}}\right)=\Phi_{x}\left(R_{2}, R_{2}, R_{N \backslash\{1,2\}}\right)=\epsilon$ (say).

Note that if $\tau\left(R_{i}\right) \neq y$ for all $i \in N \backslash\{1,2\}$ then by unanimity $\Phi_{\{x, y\}}\left(R_{N}\right)=\Phi_{x}\left(R_{N}\right)=1$, and we are done. Now suppose there is $i \in N \backslash\{1,2\}$ such that $\tau\left(R_{i}\right)=y$. Let $R \in \mathcal{D}$ be such that $\tau(R)=y$ and $U(x, R) \cap U\left(y, R_{1}\right)=\{x, y\}$. Such an $R$ exists since $\mathcal{D}$ is a binary restricted domain. Consider the preference profile $\bar{R}_{N \backslash\{1,2\}}$ of the players in $N \backslash\{1,2\}$ defined as follows: for all $i \in N \backslash\{1,2\}$

$$
\bar{R}_{i}=\left\{\begin{array}{l}
R \text { if } \tau\left(R_{i}\right)=y \\
R_{i} \text { otherwise }
\end{array}\right.
$$

\footnotetext{
${ }^{3}$ We have included the proof of Claim 1 for completeness. It can also be found in Sen (2011).
} 
By Claim 1, $\Phi_{\{x, y\}}\left(R_{1}, R_{1}, \bar{R}_{N \backslash\{1,2\}}\right)=\Phi_{\{x, y\}}\left(R_{2}, R_{2}, \bar{R}_{N \backslash\{1,2\}}\right)=1$. Since $\tau\left(R_{1}\right)=\tau\left(R_{2}\right)=x$, we have by strategy-proofness $\Phi_{x}\left(R_{1}, R_{1}, \bar{R}_{N \backslash\{1,2\}}\right)=\Phi_{x}\left(R_{1}, R_{2}, \bar{R}_{N \backslash\{1,2\}}\right)=\Phi_{x}\left(R_{2}, R_{2}, \bar{R}_{N \backslash\{1,2\}}\right)$. We show $\Phi_{x}\left(R_{1}, R_{1}, \bar{R}_{N \backslash\{1,2\}}\right)=\epsilon$. First we claim that $\Phi_{y}\left(R_{1}, R_{1}, R_{N \backslash\{1,2\}}\right)=\Phi_{y}\left(R_{1}, R_{1}, \bar{R}_{N \backslash\{1,2\}}\right)$. To see this, consider a player $i \in N \backslash\{1,2\}$ such that $R_{i} \neq \bar{R}_{i}$. Then $\tau\left(R_{i}\right)=\tau\left(\bar{R}_{i}\right)=y$, hence by strategy-proofness we have $\Phi_{y}\left(R_{1}, R_{1}, R_{i}, R_{N \backslash\{1,2, i\}}\right)=\Phi_{y}\left(R_{1}, R_{1}, \bar{R}_{i}, R_{N \backslash\{1,2, i\}}\right)$. By repeating this argument, $\Phi_{y}\left(R_{1}, R_{1}, R_{N \backslash\{1,2\}}\right)=\Phi_{y}\left(R_{1}, R_{1}, \bar{R}_{N \backslash\{1,2\}}\right)$. Hence, since $\Phi_{\{x, y\}}\left(R_{1}, R_{1}, \bar{R}_{N \backslash\{1,2\}}\right)=1$, we obtain $\Phi_{x}\left(R_{1}, R_{1}, \bar{R}_{N \backslash\{1,2\}}\right)=\epsilon$.

Using similar logic it follows that $\Phi_{y}\left(R_{1}, R_{2}, R_{N \backslash\{1,2\}}\right)=\Phi_{y}\left(R_{1}, R_{2}, \bar{R}_{N \backslash\{1,2\}}\right)$. We complete the proof by showing $\Phi_{y}\left(R_{1}, R_{2}, \bar{R}_{N \backslash\{1,2\}}\right)=1-\epsilon$. For this, since $\Phi_{x}\left(R_{1}, R_{2}, \bar{R}_{N \backslash\{1,2\}}\right)=\epsilon$, it suffices to show that $\Phi_{\{x, y\}}\left(R_{1}, R_{2}, \bar{R}_{N \backslash\{1,2\}}\right)=1$. Suppose for contradiction that $\Phi_{z}\left(R_{1}, R_{2}, \bar{R}_{N \backslash\{1,2\}}\right)>0$ for some $z \neq x, y$. Note that if $z \notin U\left(y, R_{1}\right)$ then agent 1 manipulates at $\left(R_{1}, R_{2}, \bar{R}_{N \backslash\{1,2\}}\right)$ via $R_{2}$ since $\Phi_{\{x, y\}}\left(R_{2}, R_{2}, \bar{R}_{N \backslash\{1,2\}}\right)=1$. So, $z \in U\left(y, R_{1}\right)$. Now we show that $z \in U(x, R)$. Consider $i \in N \backslash\{1,2\}$ such that $\bar{R}_{i}=R$. Let $R_{i}^{\prime}$ be such that $\tau\left(R_{i}^{\prime}\right)=x$. Then by strategy-proofness $\Phi_{U(x, R)}\left(R_{1}, R_{2}, \bar{R}_{N \backslash\{1,2\}}\right) \geq \Phi_{U(x, R)}\left(R_{1}, R_{2}, R_{i}^{\prime}, \bar{R}_{N \backslash\{1,2, i\}}\right)$. By sequentially changing the preferences of the players in $N \backslash\{1,2\}$ with $y$ at the top in this manner we construct a preference profile $\hat{R}$ such that $\tau\left(\hat{R}_{i}\right)=x$ for all $i \in N$ and $\Phi_{U(x, R)}\left(R_{1}, R_{2}, \bar{R}_{N \backslash\{1,2\}}\right) \geq \Phi_{U(x, R)}(\hat{R})=1$. Hence $\Phi_{U(x, R)}\left(R_{1}, R_{2}, \bar{R}_{N \backslash\{1,2\}}\right)=1$. However, this means $z \in U\left(y, R_{1}\right) \cap U(x, R)$, which is contradiction to $U\left(y, R_{1}\right) \cap U(x, R)=\{x, y\}$. This completes the proof of Claim 2 .

We can now complete the proof of the proposition. Let $R_{N} \in \mathcal{D}^{n}$ be an arbitrary preference profile. We show that $\Phi_{\{x, y\}}\left(R_{N}\right)=1$. In view of Claim 2, we may assume $\tau\left(R_{1}\right) \neq \tau\left(R_{2}\right)$. Note that if $\tau\left(R_{i}\right)=\{x, y\}$ for some $i \in\{1,2\}$ and $\Phi_{z}\left(R_{N}\right)>0$ for some $z \notin\{x, y\}$, then agent $i$ manipulates at $R_{N}$ via $R_{j}$, where $j \in\{1,2\}, j \neq i$, since by Claim 1 we have $\Phi_{\{x, y\}}\left(R_{j}, R_{j}, R_{N \backslash\{1,2\}}\right)=1$. So we may assume without loss of generality that $\tau\left(R_{1}\right)=x$ and $\tau\left(R_{2}\right)=y$.

Suppose $U\left(y, R_{1}\right) \cap U\left(x, R_{2}\right)=\{x, y\}$. Assume for contradiction that $\Phi_{z}\left(R_{N}\right)>0$ for some $z \notin\{x, y\}$. If $z \notin U\left(x, R_{2}\right)$, then agent 2 manipulates at $R_{N}$ via $R_{1}$ since, by Claim $1, \Phi_{\{x, y\}}\left(R_{1}, R_{1}\right.$, $\left.R_{N \backslash\{1,2\}}\right)=1$. So $z \in U\left(x, R_{2}\right)$. Similarly we have $z \in U\left(y, R_{1}\right)$, contradicting the assumption that $U\left(y, R_{1}\right) \cap U\left(x, R_{2}\right)=\{x, y\}$. Hence, $\Phi_{\{x, y\}}\left(R_{N}\right)=1$.

Finally, suppose $U\left(y, R_{1}\right) \cap U\left(x, R_{2}\right) \neq\{x, y\}$. Since $\mathcal{D}$ is a binary restricted domain there exist $R_{1}^{\prime} \in \mathcal{D}^{x}$ and $R_{2}^{\prime} \in \mathcal{D}^{y}$ such that $U\left(y, R_{1}\right) \cap U\left(x, R_{2}^{\prime}\right)=\{x, y\}$ and $U\left(y, R_{1}^{\prime}\right) \cap U\left(x, R_{2}\right)=\{x, y\}$. Since $\tau\left(R_{1}\right)=\tau\left(R_{1}^{\prime}\right)=x$ and $\tau\left(R_{2}\right)=\tau\left(R_{2}^{\prime}\right)=y$, by strategy-proofness we have $\Phi_{x}\left(R_{1}, R_{2}, R_{N \backslash\{1,2\}}\right)=$ $\Phi_{x}\left(R_{1}^{\prime}, R_{2}, R_{N \backslash\{1,2\}}\right)$ and $\Phi_{y}\left(R_{1}, R_{2}, R_{N \backslash\{1,2\}}\right)=\Phi_{y}\left(R_{1}, R_{2}^{\prime}, R_{N \backslash\{1,2\}}\right)$. By a similar argument as in the last paragraph of proof of Proposition 3.1 we have $\Phi_{x}\left(R_{1}, R_{2}^{\prime}, R_{N \backslash\{1,2\}}\right)=\Phi_{x}\left(R_{1}^{\prime}, R_{2}, R_{N \backslash\{1,2\}}\right)$. Hence, $\Phi_{\{x, y\}}\left(R_{1}, R_{2}, R_{N \backslash\{1,2\}}\right)=\Phi_{\{x, y\}}\left(R_{1}, R_{2}^{\prime}, R_{N \backslash\{1,2\}}\right)$. However, $\Phi_{\{x, y\}}\left(R_{1}, R_{2}^{\prime}, R_{N \backslash\{1,2\}}\right)=1$ since $U\left(y, R_{1}\right) \cap U\left(x, R_{2}^{\prime}\right)=\{x, y\}$, which completes the proof of the proposition.

Theorem 3.3 now follows from Propositions 3.1 and 3.2. Moreover, we have the following consequence of Theorem 3.3 and Corollary 3.1.

Corollary 3.2. Every binary restricted domain is a deterministic extreme point domain.

\subsection{Characterization of strategy-proof and unanimous rules}

In this subsection we give a characterization of all strategy-proof and unanimous PSCFs on a binary restricted domain. In view Corollary 3.2, it is sufficient to give a characterization of strategy-proof and unanimous DSCFs on a binary restricted domain.

Throughout this subsection let $\mathcal{D}$ be a binary restricted domain over $\{x, y\}$. For $R_{N} \in \mathcal{D}^{n}$, by $N^{a}\left(R_{N}\right)$ we denote the set of agents $i \in N$ such that $\tau\left(R_{i}\right)=a$; by $I\left(R_{N}\right)$ the set of agents $i \in N$ 
such that $\tau\left(R_{i}\right)=\{x, y\}$; and we define

$$
\mathcal{I}\left(R_{N}\right)=\left\{Q_{N} \in \mathcal{D}^{n}: I\left(Q_{N}\right)=I\left(R_{N}\right) \text { and } R_{i}=Q_{i} \text { for every } i \in I\left(R_{N}\right)\right\} .
$$

Further, $\hat{\mathcal{D}}^{n}=\left\{R_{N} \in \mathcal{D}^{n}: I\left(R_{N}\right) \neq N\right\}$.

In words: $\mathcal{I}\left(R_{N}\right)$ is the (equivalence) class of all preference profiles that share with $R_{N}$ the set of agents who are indifferent between $x$ and $y$ and have the same preference as in $R_{N}$; and $\hat{\mathcal{D}}^{n}$ is the set of all profiles where not all agents are indifferent between $x$ and $y$.

Definition 3.1. A function $g: \hat{\mathcal{D}}^{n} \rightarrow \mathcal{P}_{0}\left(\mathcal{P}_{0}(N)\right)$ is a minimal winning coalition function (MWCF) if

(i) $C \subseteq N \backslash I\left(R_{N}\right)$ for all $R_{N} \in \hat{\mathcal{D}}^{n}$ and all $C \in g\left(R_{N}\right)$,

(ii) $C \nsubseteq C^{\prime}$ for all $R_{N} \in \hat{\mathcal{D}}^{n}$ and $C, C^{\prime} \in g\left(R_{N}\right)$ such that $C \neq C^{\prime}$, and

(iii) $g\left(R_{N}\right)=g\left(R_{N}^{\prime}\right)$ for all $R_{N}, R_{N}^{\prime} \in \hat{\mathcal{D}}^{n}$ with $R_{N}^{\prime} \in \mathcal{I}\left(R_{N}\right)$.

The usefulness of the concept of an MWCF appears from Definition 3.5 below, where a deterministic social choice rule will be associated with it - briefly, if a minimal winning coalition has $x$ on top, then $x$ will be assigned. First we formulate some further possible properties of an MWCF.

Definition 3.2. An agent $i \in N$ is a dummy agent at $R_{N}$ for an MWCF $g$ if $i \notin I\left(R_{N}\right)$ and $i \notin C$ for all $C \in g\left(R_{N}\right)$. An agent $i$ is a nondummy agent at $R_{N}$ if $i \in C$ for some $C \in g\left(R_{N}\right)$.

Definition 3.3. An MWCF $g$ satisfies independence of dummy agents (IDA) if $g\left(R_{N}\right)=g\left(R_{i}^{\prime}, R_{N \backslash i}\right)$ for every dummy agent $i$ at $R_{N}$ for $g$ and every $R_{i}^{\prime}$ with $\tau\left(R_{i}^{\prime}\right)=\{x, y\}$.

Definition 3.4. An MWCF $g$ satisfies responsiveness to nondummy agents (RNDA) if for every nondummy agent $i$ at $R_{N}$ for $g$ and every $R_{i}^{\prime} \in \mathcal{D}$ with $\tau\left(R_{i}^{\prime}\right)=\{x, y\}$ we have

(i) for all $C \in g\left(R_{N}\right)$ with $i \notin C$, there exists a $C^{\prime} \subseteq C$ such that $C^{\prime} \in g\left(R_{i}^{\prime}, R_{N \backslash i}\right)$, and

(ii) for all $C \in g\left(R_{i}^{\prime}, R_{N \backslash i}\right)$ such that $C \notin g\left(R_{N}\right)$ there is $C^{\prime} \in g\left(R_{N}\right)$ with $i \in C^{\prime}$ such that $C^{\prime} \backslash i \subseteq C$.

In the theorem below we provide a characterization of all strategy-proof and unanimous PSCFs, based on the following concept.

Definition 3.5. A deterministic social choice function $f: \mathcal{D}^{n} \rightarrow A$ is a generalized voting by committee rule if there exists a minimal winning coalition function $g$ satisfying IDA and RNDA and such that for all $R_{N} \in \hat{\mathcal{D}}^{n}$, we have: $f\left(R_{N}\right)=x$ if and only if $C \subseteq N^{x}\left(R_{N}\right)$ for some $C \in g\left(R_{N}\right)$.

Note that the DSCF $f$ in Definition 3.5 is not completely determined by the mwcf $g$, since $f\left(R_{N}\right)$ is yet undetermined if $I\left(R_{N}\right)=N$, i.e., if all agents are indifferent between $x$ and $y$.

Theorem 3.4. A probabilistic social choice function on $\mathcal{D}^{n}$ is strategy-proof and unanimous if and only if it is a convex combination of generalized voting by committee rules.

Proof. In view of Corollary 3.2 it is sufficient to prove the theorem for deterministic social choice functions.

For the if-part, let $f$ be a generalized voting by committee rule, and let $g$ be the associated MWCF as in Definition 3.5. We show that $f$ is unanimous and strategy-proof. 
To show unanimity, consider a profile $R_{N} \in \hat{\mathcal{D}}^{n}$ such that $\cap_{i \in N} \tau\left(R_{i}\right) \neq \emptyset$. If $\tau\left(R_{i}\right)=\{x, y\}$ for all $i \in N$ then unanimity holds by Theorem 3.3. Now assume without loss of generality that $\cap_{i \in N} \tau\left(R_{i}\right)=x$. Then $N^{x}\left(R_{N}\right)=N \backslash I\left(R_{N}\right)$. Since $g\left(R_{N}\right) \subseteq \mathcal{P}_{0}\left(N \backslash I\left(R_{N}\right)\right)=\mathcal{P}_{0}\left(N^{x}\left(R_{N}\right)\right)$, we have $f\left(R_{N}\right)=x$.

To show strategy-proofness, let $R_{N} \in \hat{\mathcal{D}}^{n}$. If $i \in I\left(R_{N}\right)$ then $i$ cannot manipulate. Otherwise, $i$ is either a dummy agent or a nondummy agent.

Suppose $i$ is a dummy agent at $R_{N}$, let $R_{i}^{\prime} \in \mathcal{D}$ and let $R_{N}^{\prime}=\left(R_{i}^{\prime}, R_{N \backslash i}\right)$. If $i \notin I\left(R_{N}^{\prime}\right)$ then by property (iii) of $g, g\left(R_{N}\right)=g\left(R_{N}^{\prime}\right)$ and hence $f\left(R_{N}\right)=f\left(R_{N}^{\prime}\right)$. If $i \in I\left(R_{N}^{\prime}\right)$ then $g\left(R_{N}\right)=g\left(R_{N}^{\prime}\right)$ by IDA of $g$ and hence $f\left(R_{N}\right)=f\left(R_{N}^{\prime}\right)$. Hence, a dummy agent $i$ cannot manipulate.

Suppose, finally, that $i$ is a nondummy agent at $R_{N}$. Let $R_{i}^{\prime} \in \mathcal{D}$. We distinguish two cases in which $i$ could possibly manipulate via $R_{i}^{\prime}$.

First, suppose $\tau\left(R_{i}\right)=y$ and $f\left(R_{N}\right)=x$. Then there is $C \in g\left(R_{N}\right)$ such that $C \subseteq N^{x}\left(R_{N}\right)$. Now, if $\tau\left(R_{i}^{\prime}\right)=x$ then by (iii) in the definition of $g$ we have $g\left(R_{N}\right)=g\left(R_{N}^{\prime}\right)$ and hence $f\left(R_{N}\right)=$ $f\left(R_{N}^{\prime}\right)$. If $\tau\left(R_{i}^{\prime}\right)=\{x, y\}$ then by (i) in RNDA, $C^{\prime} \in g\left(R_{N}^{\prime}\right)$ for some $C^{\prime} \subseteq C$, and hence $f\left(R_{N}\right)=$ $f\left(R_{N}^{\prime}\right)$.

Second, suppose $\tau\left(R_{i}\right)=x$ and $f\left(R_{N}\right)=y$. Then for all $C \in g\left(R_{N}\right)$ there is $j \in C, j \neq i$, such that $\tau\left(R_{j}\right)=y$. If $i \notin I\left(R_{N}^{\prime}\right)$ then again $g\left(R_{N}\right)=g\left(R_{N}^{\prime}\right)$ by (iii) in the definition of $g$, hence $f\left(R_{N}\right)=f\left(R_{N}^{\prime}\right)$. If $i \in I\left(R_{N}^{\prime}\right)$, then from (ii) in RNDA it follows that for all $C \in g\left(R_{N}^{\prime}\right)$ there is $j \in C$ such that $\tau\left(R_{j}\right)=y$. So $f\left(R_{N}^{\prime}\right)=y=f\left(R_{N}^{\prime}\right)$.

Hence, also a nondummy agent $i$ does not manipulate, and we conclude that $f$ is strategy-proof.

For the only-if part, let $f$ be a strategy-proof and unanimous deterministic social choice function $\mathcal{D}^{n}$. Let $R_{N} \in \hat{\mathcal{D}}^{n}$. Let $C \subseteq N \backslash I\left(R_{N}\right)$ satisfy

(c1) $f\left(R_{N}^{\prime}\right)=x$ for all $R_{N}^{\prime} \in \mathcal{I}\left(R_{N}\right)$ such that $N^{x}\left(R_{N}^{\prime}\right)=C$, and

(c2) $f\left(R_{N}^{\prime}\right)=y$ for all $R_{N}^{\prime} \in \mathcal{I}\left(R_{N}\right)$ such that $N^{x}\left(R_{N}^{\prime}\right) \varsubsetneqq C$.

We define $g\left(R_{N}\right)=\left\{C \subseteq N \backslash I\left(R_{N}\right): C\right.$ satisfies (c1) and (c2) $\}$. By unanimity of $f, g\left(R_{N}\right) \in$ $\mathcal{P}_{0}\left(\mathcal{P}_{0}(N)\right)$. Clearly, $g$ satisfies (i), (ii), and (iii) in Definition 3.1. Hence, $g$ is an MWCF. If $C \subseteq N^{x}\left(R_{N}\right)$ for some $R_{N} \in \mathcal{D}^{n}$ and $C \in g\left(R_{N}\right)$, then $f\left(R_{N}\right)=x$ by strategy-proofness of $f$. If $f\left(R_{N}\right)=x$ for some $R_{N} \in \mathcal{D}^{n}$, then clearly there is $C \subseteq N^{x}\left(R_{N}\right)$ such that $C \in g\left(R_{N}\right)$. Hence, $f$ is a generalized voting by committee rule associated with $g$, provided we show that $g$ satisfies IDA and RNDA.

In order to show IDA of $g$, let $R_{N} \in \hat{\mathcal{D}}^{n}, i \in N$ such that $i \notin I\left(R_{N}\right)$ and $i \notin C$ for all $C \in g\left(R_{N}\right)$, and let $R_{i}^{\prime} \in \mathcal{D}$ with $\tau\left(R_{i}^{\prime}\right)=\{x, y\}$. Write $R_{N}^{\prime}=\left(R_{N \backslash i}, R_{i}^{\prime}\right)$. We have to show that $g\left(R_{N}\right)=g\left(R_{N}^{\prime}\right)$.

First, let $C^{\prime} \in g\left(R_{N}\right)$. Consider $Q_{N} \in \mathcal{I}\left(R_{N}^{\prime}\right)$ such that $N^{x}\left(Q_{N}\right)=C^{\prime}$. Let $Q_{i}^{\prime} \in \mathcal{D}$ with $\tau\left(Q_{i}^{\prime}\right)=y$. Hence $\left(Q_{N \backslash i}, Q_{i}^{\prime}\right) \in \mathcal{I}\left(R_{N}\right)$. Since $C^{\prime} \in g\left(R_{N}\right)$ we have $f\left(Q_{N \backslash i}, Q_{i}^{\prime}\right)=x$. This implies $f\left(Q_{N}\right)=x$, otherwise $i$ manipulates at $\left(Q_{N \backslash i}, Q_{i}^{\prime}\right)$ via $Q_{i}$. Next, let $C^{\prime \prime} \subsetneq C^{\prime}$ and now consider a profile $V_{N} \in \mathcal{I}\left(R_{N}^{\prime}\right)$ such that $N^{x}\left(V_{N}\right)=C^{\prime \prime}$; and let $V_{i}^{\prime} \in \mathcal{D}$ with $\tau\left(V_{i}^{\prime}\right)=x$. Hence $\left(V_{N \backslash i}, V_{i}^{\prime}\right) \in \mathcal{I}\left(R_{N}\right)$. Since $C^{\prime \prime} \subsetneq C^{\prime}$ and $i \notin C$ for all $C \in g\left(R_{N}\right)$, we now have $f\left(V_{N \backslash i}, V_{i}^{\prime}\right)=y$. This implies $f\left(V_{N}\right)=y$, otherwise $i$ manipulates at $\left(V_{N \backslash i}, V_{i}^{\prime}\right)$ via $V_{i}$. Altogether, $C^{\prime} \in g\left(R_{N}^{\prime}\right)$.

Second, let $C^{\prime} \in g\left(R_{N}^{\prime}\right)$. Consider $Q_{N} \in \mathcal{I}\left(R_{N}^{\prime}\right)$ such that $N^{x}\left(Q_{N}\right)=C^{\prime}$. Then $f\left(Q_{N}\right)=x$. Let $Q_{i}^{\prime} \in \mathcal{D}$ with $\tau\left(Q_{i}^{\prime}\right)=x$. Then $f\left(Q_{N \backslash i}, Q_{i}^{\prime}\right)=x$ otherwise $i$ manipulates at $\left(Q_{N \backslash i}, Q_{i}^{\prime}\right)$ via $Q_{i}$. Next, let $C^{\prime \prime} \subsetneq C^{\prime}$ and now consider a profile $V_{N} \in \mathcal{I}\left(R_{N}^{\prime}\right)$ such that $N^{x}\left(V_{N}\right)=C^{\prime \prime}$. Then $f\left(V_{N}\right)=y$. Let $V_{i}^{\prime} \in \mathcal{D}$ with $\tau\left(V_{i}^{\prime}\right)=y$. Then $f\left(V_{N \backslash i}, V_{i}^{\prime}\right)=y$, otherwise $i$ manipulates at $\left(V_{N \backslash i}, V_{i}^{\prime}\right)$ via $V_{i}$. Altogether, $C^{\prime} \in g\left(R_{N}\right)$. This concludes the proof of IDA of $g$.

Finally we show that $g$ satisfies RNDA. Let $R_{N} \in \hat{\mathcal{D}}^{n}$ and $i \in N$ such that $i \in C$ for some $C \in g\left(R_{N}\right)$, and let $R_{i}^{\prime} \in \mathcal{D}$ such that $\tau\left(R_{i}^{\prime}\right)=\{x, y\}$. Write $R_{N}^{\prime}=\left(R_{N \backslash i}, R_{i}^{\prime}\right)$. 
To show (i) in RNDA, suppose that $C \in g\left(R_{N}\right)$ with $i \notin C$. Consider a profile $Q_{N} \in \mathcal{I}\left(R_{N}^{\prime}\right)$ such that $N^{x}\left(Q_{N}\right)=C$. Let $Q_{i}^{\prime} \in \mathcal{D}$ with $\tau\left(Q_{i}^{\prime}\right)=y$. Write $Q_{N}^{\prime}=\left(Q_{N \backslash i}, Q_{i}^{\prime}\right)$. Since $f\left(Q_{N}^{\prime}\right)=x$, we must have $f\left(Q_{N}\right)=x$ otherwise $i$ manipulates at $Q_{N}^{\prime}$ via $R_{i}^{\prime}$. This implies the existence of a $C^{\prime} \subseteq C$ with $C^{\prime} \in g\left(R_{N}^{\prime}\right)$.

To show (ii) in RNDA, suppose that $C \in g\left(R_{N}^{\prime}\right) \backslash g\left(R_{N}\right)$, so in particular $i \notin C$. Consider a profile $Q_{N} \in \mathcal{I}\left(R_{N}^{\prime}\right)$ such that $N^{x}\left(Q_{N}\right)=C$. Then $f\left(Q_{N}\right)=x$. Let $Q_{i}^{\prime} \in \mathcal{D}$ with $\tau\left(Q_{i}^{\prime}\right)=x$. Write $Q_{N}^{\prime}=\left(Q_{N \backslash i}, Q_{i}^{\prime}\right)$. If $f\left(Q_{N}^{\prime}\right)=y$ then $i$ manipulates at $Q_{N}^{\prime}$ via $Q_{i}\left(=R_{i}^{\prime}\right)$. Hence $f\left(Q_{N}^{\prime}\right)=x$, so since $N^{x}\left(Q_{N}^{\prime}\right)=C \cup i$ there must be a $C^{\prime} \in g\left(R_{N}\right)$ such that $C^{\prime} \subseteq C \cup i$. Since $C \notin g\left(R_{N}\right), C^{\prime} \neq C$. If $C^{\prime} \varsubsetneqq C$, then consider $V_{N} \in \mathcal{I}\left(R_{N}\right)$ with $N^{x}\left(V_{N}\right)=C^{\prime}$. Then $f\left(V_{N}\right)=x$ and $f\left(V_{N \backslash i}, R_{i}^{\prime}\right)=y$, so that $i$ manipulates at $V_{N}$ via $R_{i}^{\prime}$. Hence, we have $i \in C^{\prime}$ and $C^{\prime} \backslash i \subseteq C$.

\subsection{A necessary condition for binary support}

Theorem 3.3 shows that binary restrictedness is a sufficient condition for a domain to be a binary support domain, i.e., for every strategy-proof and unanimous probabilistic social choice function to have binary support. In this section we provide a necessary condition, which is a slight weakening of binar restrictedness.

Definition 3.6. The support of a PSCF $\Phi$ on a domain $\mathcal{D}$ is the set $\operatorname{Supp}(\Phi)=\left\{x \in A: \Phi_{x}\left(R_{N}\right)>\right.$ 0 for some $\left.R_{N} \in \mathcal{D}^{n}\right\}$.

Definition 3.7. For $x, y \in A, x \neq y$, a set $\mathcal{D} \subseteq \mathbb{W}(A)$ is an almost binary restricted domain if

(i) for all $R \in \mathcal{D}, \tau(R) \in\{\{x\},\{y\},\{x, y\}\}$,

(ii) for all $a, b \in\{x, y\}, a \neq b$, suppose that there are $z_{R} \in U(b, R) \backslash\{a, b\}$ for all $R \in \mathcal{D}^{a}$ such that $z_{R} R z_{R^{\prime}}$ for all $R, R^{\prime} \in \mathcal{D}^{a}$; then not both (a) and (b) can hold, where

(a) for each $R^{\prime} \in \mathcal{D}^{b}$, either $z_{R} \in U\left(a, R^{\prime}\right)$ for all $R \in \mathcal{D}^{a}$, or $z_{R} \notin U\left(a, R^{\prime}\right)$ for all $R \in \mathcal{D}^{a}$,

(b) there exists $R^{\prime} \in \mathcal{D}^{b}$ such that $z_{R} \in U\left(a, R^{\prime}\right)$ for all $R \in \mathcal{D}^{a}$.

It is not difficult to verify that every binary restricted domain is an almost binary restricted domain.

Theorem 3.5. Every binary support domain is an almost binary restricted domain.

Proof. Let $\mathcal{D}$ be a binary support domain over $\{x, y\}$. We show that $\mathcal{D}$ is an almost binary restricted domain over $\{x, y\}$.

Assume for contradiction that $\mathcal{D}$ does not satisfy condition (i) in Definition 3.7. We construct a strategy-proof and unanimous PSCF on $\mathcal{D}^{n}$ that does not have binary support.

First, suppose there exists $R \in \mathcal{D}$ with $\tau(R) \cap\{x, y\}=\emptyset$. Then for a strategy-proof and unanimous PSCF $\Phi$ we have $\Phi_{x}\left(R_{N}\right)=\Phi_{y}\left(R_{N}\right)=0$ where $R_{i}=R$ for all $i \in N$, contradicting the assumption that $\mathcal{D}$ is a binary support domain over $\{x, y\}$. Therefore, $\tau(R) \cap\{x, y\} \neq \emptyset$ for all $R \in \mathcal{D}$. Now assume $\cup_{R \in \mathcal{D}} \tau(R) \supseteq\{x, y, z\}$ for some $z \in A$. For $R \in \mathcal{D}$ and $X \subseteq A$, we denote $B_{R}(X)=\{z: z R x$ for all $x \in X\}$. Note that $B_{R}(A)=\tau(R)$. Consider the PSCF

$$
\Phi\left(R_{N}\right)=U\left(B_{R_{n}}\left(B_{R_{n-1}}\left(\ldots\left(B_{R_{2}}\left(B_{R_{1}}(A)\right)\right) \ldots\right)\right)\right)
$$

where $U(S)$ denotes the uniform probability distribution over the elements in the set $S$. 
The PSCF $\Phi$ is unanimous by definition. To see that $\{x, y, z\} \subseteq \operatorname{Supp}(\Phi)$ consider the unanimous profile $R_{N}$ where $R_{i}=R_{j}$ for all $i, j \in N$ and $z \in \tau\left(R_{1}\right)$. By the definition of $\Phi, z$ gets positive probability at this profile. It remains to show that $\Phi$ is strategy-proof. Agent 1 cannot manipulate $\Phi$ since $\Phi_{\tau\left(R_{1}\right)}\left(R_{N}\right)=1$ for all $R_{N} \in \mathcal{D}^{n}$. Suppose the agents $1,2, \ldots, k$ cannot manipulate $\Phi$. We show agent $k+1$ cannot manipulate $\Phi$. Note that $B_{R_{k+1}}(X) R_{k+1} B_{R_{k+1}^{\prime}}(X)$ for all $X \subseteq A$, $R_{k+1}$ and $R_{k+1}^{\prime}$. This, together with the fact that $\Phi_{B_{R_{k+1}}(X)}\left(R_{N}\right)=1$ for all $R_{N} \in \mathcal{D}^{n}$ where $X=B_{R_{k}}\left(B_{R_{k-1}}\left(\ldots\left(B_{R_{2}}\left(B_{R_{1}}(A)\right)\right) \ldots\right)\right)$, implies that agent $k+1$ cannot manipulate $\Phi$. This proves that $\Phi$ is strategy-proof.

We conclude that $\mathcal{D}$ satisfies condition (i) in Definition 3.7. Suppose that $\mathcal{D}$ does not satisfy condition (ii). We construct again a strategy-proof and unanimous PSCF $\Phi$ that does not have binary support. Since condition (ii) is not satisfied there are, without loss of generality, $z_{R} \in$ $U(y, R)$ for all $R \in \mathcal{D}^{x}$, such that $z_{R} R z_{R^{\prime}}$ for all $R, R^{\prime} \in \mathcal{D}^{x}$, and such that $\mathcal{D}^{y}=\mathcal{D}_{1}^{y} \cup \mathcal{D}_{2}^{y}$ with $\mathcal{D}_{1}^{y}=\left\{R \in \mathcal{D}^{y}: z_{R^{\prime}} \notin U(x, R)\right.$ for all $\left.R^{\prime} \in \mathcal{D}^{x}\right\}$ and $\mathcal{D}_{2}^{y}=\left\{R \in \mathcal{D}^{y}: z_{R^{\prime}} \in U(x, R)\right.$ for all $\left.R^{\prime} \in \mathcal{D}^{x}\right\}$ and with $\mathcal{D}_{2}^{y} \neq \emptyset$. Consider the rule $\Phi$ defined as follows:

$$
\Phi\left(R_{N}\right)=\left\{\begin{array}{l}
U\left(\tau\left(R_{1}\right) \cap \tau\left(R_{2}\right) \cap \ldots \cap \tau\left(R_{n}\right)\right) \text { if } \tau\left(R_{1}\right) \cap \tau\left(R_{2}\right) \cap \ldots \cap \tau\left(R_{n}\right) \neq \emptyset \\
U\left(\tau\left(R_{1}\right) \cap \tau\left(R_{2}\right)\right) \text { if } \tau\left(R_{1}\right) \cap \tau\left(R_{2}\right) \cap \ldots \cap \tau\left(R_{n}\right)=\emptyset \text { and } \tau\left(R_{1}\right) \cap \tau\left(R_{2}\right) \neq \emptyset \\
\Phi_{\left(x, z_{1}, y\right)}\left(R_{N}\right)=\left(\frac{1}{3}, \frac{1}{6}, \frac{1}{2}\right) \text { if } R_{1} \in \mathcal{D}^{x}, R_{2} \in \mathcal{D}_{2}^{y} \\
\Phi_{(x, y)}\left(R_{N}\right)=\left(\frac{1}{2}, \frac{1}{2}\right) \text { if } R_{1} \in \mathcal{D}^{x}, R_{2} \in \mathcal{D}_{1}^{y} \\
\Phi_{(x, y)}\left(R_{N}\right)=\left(\frac{1}{2}, \frac{1}{2}\right) \text { if } R_{1} \in \mathcal{D}^{y} \text { and } R_{2} \in \mathcal{D}^{x}
\end{array}\right.
$$

where $\Phi_{\left(x, z_{R_{1}}, y\right)}\left(R_{N}\right)=\left(\frac{1}{3}, \frac{1}{6}, \frac{1}{2}\right)$ means that $\Phi_{x}\left(R_{N}\right)=\frac{1}{3}, \Phi_{z_{R_{1}}}\left(R_{N}\right)=\frac{1}{6}$, and $\Phi_{z_{R_{1}}}\left(R_{N}\right)=\frac{1}{3}$.

By definition $\Phi$ is unanimous and does not have binary support. We show that $\Phi$ is strategy-proof. It is easy to see that no agent other than 1 and 2 manipulates $\Phi$. Moreover, it is clear that agents 1 and 2 do not manipulate if $\tau\left(R_{1}\right) \cap \tau\left(R_{2}\right) \neq \emptyset$. Consider a profile $R_{N}$ where $R_{1} \in \mathcal{D}^{x}$ and $R_{2} \in \mathcal{D}^{y}$. Agent 1 does not manipulate, in particular since $z_{R_{1}} R_{1} z_{R_{1}^{\prime}}$ for all $R_{1}, R_{1}^{\prime} \in \mathcal{D}^{x}$. Agent 2 does manipulate since either $z_{R_{1}} \in U\left(x, R_{2}\right)$ for all $R_{1} \in \mathcal{D}^{x}$, or $z_{R_{1}} \notin U\left(x, R_{2}\right)$ for all $R_{1} \in \mathcal{D}^{x}$. Finally, consider a profile where $R_{1} \in \mathcal{D}^{y}$ and $R_{2} \in \mathcal{D}^{x}$. Note that the outcome does not change if an agent changes his preference while keeping the top same. If an agent changes his top then the top of the other agent gets probability 1 . This proves that $\Phi$ is strategy-proof.

\section{Applications}

In this section we provide a few examples of domains that are binary restricted. One example is the domain of single-dipped preference relations relative to a given order of the alternatives. Another example is the domain of single-peaked preferences where the peaks are restricted to be one of two adjacent alternatives. A third example is the single-crossing domain with two tops.

\subsection{Single-dipped domain}

In this section we apply our results to single-dipped domains and characterize all strategy-proof and unanimous PSCFs on this domain.

Definition 4.1. A preference of agent $i \in N, R_{i} \in \mathbb{W}(A)$, is single-dipped on $A$ relative to a linear ordering $\succ$ of the set of alternatives if

(i) $R_{i}$ has a unique minimal element $d\left(R_{i}\right)$, the dip of $R_{i}$ and

(ii) for all $y, z \in A,\left[d\left(R_{i}\right) \succeq y \succ z\right.$ or $\left.z \succ y \succeq d\left(R_{i}\right)\right] \Rightarrow z P_{i} y$. 
Let $\mathcal{D}_{\succ}$ denote the set of all single-dipped preferences relative to the ordering $\succ$, and let $\mathcal{R}_{\succ} \subseteq$ $\mathcal{D}_{\succ}$. Clearly $\mathcal{D}_{\succ}$ is a binary restricted domain. Moreover, $\mathcal{R}_{\succ}$ is a binary restricted domain if it satisfies condition (ii) in Definition 2.9, the definition of a binary restricted domain. Hence, by Corollary 3.2 and Theorem 3.4 we obtain the following result.

Corollary 4.1. Let $\succ$ be a linear ordering over $A$ and let $\mathcal{R}_{\succ} \subseteq \mathcal{D}_{\succ}$ satisfy (ii) in Definition 2.9. Then a probabilistic social choice function on $\mathcal{R}_{\succ}^{n}$ is strategy-proof and unanimous if and only if it is convex combination of generalized voting by committee rules on $\mathcal{R}_{\succ}^{n}$.

Consider a single-dipped domain where the alternatives are assumed to be equidistant from each other and preference is consistent with the distance from the dip. More precisely, when the distance of an alternative from the dip of an agent is higher than that of another alternative, the agent prefers the former alternative to the latter. Call such a domain a 'distance single-dipped domain'. If ties between equi-distant alternatives are broken in both ways, then such a domain is again a binary restricted domain, and Corollary 4.1 applies. However, if ties are broken in favor of the left side (or of the right side) only, then the domain is no longer a binary restricted domain nor even an almost binary restricted domain. Indeed, in Example 4.1 we show that there exists a strategy-proof and unanimous probabilistic rule that does not have binary support.

Example 4.1. Consider the distance single-dipped domain presented in the table below. There two agents and four alternatives: think of the alternatives as located on a line in the ordering $x_{1}<x_{2}<x_{3}<x_{4}$ with equal distances. Ties are always broken in favor of the left alternative. It is not hard to verify that the PSCF given in the table (probabilities in the order $x_{1}, x_{2}, x_{3}, x_{4}$, and $0<\beta<\alpha<1,0<\gamma<\epsilon<1$ arbitrary) is strategy-proof and unanimous, but does not have binary support.

\begin{tabular}{|c|c|c|c|c|}
\hline $1 \backslash 2$ & $x_{1} x_{2} x_{3} x_{4}$ & $x_{4} x_{3} x_{2} x_{1}$ & $x_{4} x_{1} x_{3} x_{2}$ & $x_{1} x_{2} x_{4} x_{3}$ \\
\hline$x_{1} x_{2} x_{3} x_{4}$ & $(1,0,0,0)$ & $(\alpha-\beta, \beta, 0,1-\alpha)$ & $(\alpha, 0,0,1-\alpha)$ & $(1,0,0,0)$ \\
\hline$x_{4} x_{3} x_{2} x_{1}$ & $(\epsilon-\gamma, \gamma, 0,1-\epsilon)$ & $(0,0,0,1)$ & $(0,0,0,1)$ & $(\epsilon-\gamma, \gamma, 0,1-\epsilon)$ \\
\hline$x_{4} x_{1} x_{3} x_{2}$ & $(\epsilon, 0,0,1-\epsilon)$ & $(0,0,0,1)$ & $(0,0,0,1)$ & $(\epsilon, 0,0,1-\epsilon)$ \\
\hline$x_{1} x_{2} x_{4} x_{3}$ & $(1,0,0,0)$ & $(\alpha-\beta, \beta, 0,1-\alpha)$ & $(\alpha, 0,0,1-\alpha)$ & $(1,0,0,0)$ \\
\hline
\end{tabular}

\subsection{Single-peaked domain with two adjacent alternatives as peak}

Another well-known domain of preferences is the single-peaked domain.

Definition 4.2. A preference of agent $i \in N, R_{i} \in \mathbb{W}(A)$, is single-peaked on $A$ relative to a linear ordering $\succ$ of the set of alternatives if

(i) $R_{i}$ has a unique maximal element $\tau\left(R_{i}\right)$, the peak of $R_{i}$ and

(ii) for all $y, z \in A,\left[\tau\left(R_{i}\right) \succeq y \succ z\right.$ or $\left.z \succ y \succeq d\left(R_{i}\right)\right] \Rightarrow y P_{i} z$.

Clearly, if there are at least three alternatives, then the domain of all single-peaked preferences is not a binary restricted domain. However, a subset of the single-peaked domain where peaks are restricted to a set of two adjacent alternatives is a binary restricted domain over those two adjacent alternatives. Formally:

Definition 4.3. A set $\mathcal{R}^{\succ}$ of single-peaked preferences relative to the linear ordering $\succ$ of $A$ is an adjacent single-peaked domain if there exist alternatives $x, y \in A$ with $x \succ y$ and $z \succ x$ or $y \succ z$ for all $z \in A \backslash\{x, y\}$, such that $\tau(R) \in\{x, y\}$ for all $R \in \mathcal{R}^{\succ}$. 
It can be easily seen that an adjacent single-peaked domain is a binary restricted domain. By Corollary 3.2 and Theorem 3.4 again we obtain the following result.

Corollary 4.2. Let $\succ$ be a linear ordering over $A$ and let $\mathcal{R}^{\succ}$ be an adjacent single-peaked domain. Then a probabilistic social choice function on $\left(\mathcal{R}^{\succ}\right)^{n}$ is strategy-proof and unanimous if and only if it is convex combination of generalized voting by committee rules on $\left(\mathcal{R}^{\succ}\right)^{n}$.

\subsection{Maximal Single Crossing with two tops}

Another well-known domain of preferences is the single-crossing domain of antisymmetric preferences which is defined below.

Definition 4.4. A set of antisymmetric preferences $\mathcal{D} \subseteq \mathbb{W}(A)$ is a single-crossing domain if there are linear orderings $\succ$ on $A$ and $>$ on $\mathcal{D}$ such that for all $x, y \in A$ and $R, R^{\prime} \in \mathcal{D}$,

$$
\left[y \succ x, R^{\prime}>R, \text { and } y R x\right] \Longrightarrow y R^{\prime} x
$$

and

$$
\left[y \succ x, R^{\prime}>R \text {, and } x R^{\prime} y\right] \Longrightarrow x R y .
$$

A single-crossing domain $\mathcal{D}$ is maximal if there does not exist a single-crossing domain $\mathcal{D}^{\prime} \subseteq$ $\mathbb{W}(A)$ such that $\mathcal{D} \varsubsetneqq \mathcal{D}^{\prime}{ }^{4}$ In a maximal single-crossing domain with two tops, only two alternatives come as top alternatives, i.e., for any preference in the domain one of these two alternatives is the most preferred alternative of that preference. It can be seen that such a domain is a binary restricted domain, so that by Corollary 3.2 and Theorem 3.4 we obtain again:

Corollary 4.3. Let $\mathcal{D}$ be a maximal single-crossing domain with two tops. Then a probabilistic social choice function on $\mathcal{D}^{n}$ is strategy-proof and unanimous if and only if it is convex combination of generalized voting by committee rules on $\mathcal{D}^{n}$.

\section{$5 \quad$ Infinitely many alternatives}

In this section we assume that the set of alternatives $A$ may be an infinite set, for instance a closed interval in $\mathbb{R}$. We assume $A$ to be endowed with a $\sigma$-algebra of measurable sets; only preferences in $\mathbb{W}(A)$ for which the upper contour sets $U(x, R), x \in A$, are measurable, are considered. A PSCF $\Phi$ assigns to an admissible preference profile a probability distribution over the measurable space $A$, hence a probability to every measurable set. Most of the introduced concepts and definitions extend in a straightforward manner to this setting. By modifying its proof, Theorem 3.3 can be seen to still hold: a binary restricted domain over $\{x, y\}(x, y \in A)$ is a binary support domain. The main purpose of this section is to provide a characterization of all strategy-proof and unanimous PSCFs on a binary restricted domain.

Let $\mathcal{D}$ be a binary restricted domain over $\{x, y\}$ for some $x, y \in A$. We use some of the notations introduced in Section 3.3. For $I \in \mathcal{P}(N) \backslash\{N\}$ let $h(I): \mathcal{P}(N \backslash I) \rightarrow[0,1]$ satisfy $h(I)(\emptyset)=0$, $h(I)(N \backslash I)=1$, and $h(I)(C) \leq h(I)\left(C^{\prime}\right)$ for all $C, C^{\prime} \in \mathcal{P}(N \backslash I)$ with $C \subseteq C^{\prime}$. The map $h$ defined

\footnotetext{
${ }^{4}$ An equivalent way to describe a maximal single-crossing domain is as follows. Start from an arbitrary preference $R$ and make a path to the opposite preference $-R$ by swapping two alternatives each time, but only once on the path.
} 
on $R_{N} \in \hat{\mathcal{D}}^{n}$ is a probabilistic minimal winning coalition function (pmwcf). A pmwcf $h$ is monotonic if

$$
h(I)(C \backslash i) \leq h\left(I^{\prime}\right)(C \backslash i) \leq h(I)(C)
$$

for all $I \in \mathcal{P}(N) \backslash\{N\}, C \in \mathcal{P}(N \backslash I), i \in C, I^{\prime}=I \cup i$.

The preceding definitions are somewhat technical, but they formalize the same ideas as those underlying a (deterministic) winning coalition function: $h(I)(C)$ can now be interpreted as the probability that a coalition $C$ is winning given a profile with $I$ as the set of agents who are indifferent between $x$ and $y$; specifically, if $C$ is the set of agents with $x$ on top, then this probability will be assigned to $x$. This is formalized in the following definition.

Definition 5.1. A PSCF $\Phi$ on $\mathcal{D}^{n}$ is a probabilistic generalized voting by committee rule (PGVCR) if $\Phi_{\{x, y\}}\left(R_{N}\right)=1$ for all $R_{N} \in \mathcal{D}^{n}$, and there exists a monotonic pmwcf $h$ such that for all $R_{N} \in \hat{\mathcal{D}}^{n}$, $\Phi_{x}\left(R_{N}\right)=h\left(I\left(R_{N}\right)\right)\left(N^{x}\left(R_{N}\right)\right)$.

We have the following result.

Theorem 5.1. Let $\mathcal{D}$ be a binary restricted domain over $\{x, y\}$. A PSCF $\Phi$ on $\mathcal{D}^{n}$ is strategy-proof and unanimous if and only if it is a probabilistic generalized voting by committee rule.

Proof. For the if part, let $\Phi$ be a PGVCR. Then for all $R_{N} \in \mathcal{D}^{n}, \Phi_{\{x, y\}}\left(R_{N}\right)=1$ and there exists a monotonic pmwcf $h$ such that $\Phi_{x}\left(R_{N}\right)=h\left(I\left(R_{N}\right)\right)\left(N^{x}\left(R_{N}\right)\right)$ for all $R_{N} \in \hat{\mathcal{D}}^{n}$. We show that $\Phi$ is unanimous and strategy-proof.

We first show that $\Phi$ is unanimous. Consider a profile $R_{N} \in \mathcal{D}^{n}$ such that $\cap_{i \in N} \tau\left(R_{i}\right) \neq \emptyset$. If $\tau\left(R_{i}\right)=\{x, y\}$ for all $i \in N$ then unanimity holds trivially. Suppose $\cap_{i \in N} \tau\left(R_{i}\right)=x$. Then $N^{x}\left(R_{N}\right)=N \backslash I\left(R_{N}\right)$. Since $h\left(I\left(R_{N}\right)\right)\left(N \backslash I\left(R_{N}\right)\right)=1$, we have $\Phi_{x}\left(R_{N}\right)=1$. On the other hand, if $\cap_{i \in N} \tau\left(R_{i}\right)=y$ then $N^{x}\left(R_{N}\right)=\emptyset$ which implies $\Phi_{x}\left(R_{N}\right)=h\left(I\left(R_{N}\right)\right)(\emptyset)=0$. So, $\Phi_{y}\left(R_{N}\right)=1$.

Now we show that $\Phi$ is strategy-proof. Consider a profile $R_{N} \in \hat{\mathcal{D}}^{n}$. The agents in $I\left(R_{N}\right)$ do not manipulate. Let $i \in N \backslash I\left(R_{N}\right)$. Let $R_{i}^{\prime} \in \mathcal{D}$ and write $R_{N}^{\prime}=\left(R_{N \backslash i}, R_{i}^{\prime}\right)$. We distinguish four cases and each time show that $i$ does not manipulate. (i) If $\tau\left(R_{i}\right)=x$ and $\tau\left(R_{i}^{\prime}\right)=y$ then $\Phi_{x}\left(R_{N}\right)=$ $h\left(I\left(R_{N}\right)\right)\left(N^{x}\left(R_{N}\right)\right) \geq h\left(I\left(R_{N}\right)\right)\left(N^{x}\left(R_{N}\right) \backslash i\right)=h\left(I\left(R_{N}^{\prime}\right)\right)\left(N^{x}\left(R_{N}^{\prime}\right)\right)=\Phi_{x}\left(R_{N}^{\prime}\right)$ by definition of a pmwcf. (ii) If $\tau\left(R_{i}\right)=y$ and $\tau\left(R_{i}^{\prime}\right)=x$ then $\Phi_{x}\left(R_{N}\right)=h\left(I\left(R_{N}\right)\right)\left(N^{x}\left(R_{N}\right)\right) \leq h\left(I\left(R_{N}\right)\right)\left(N^{x}\left(R_{N}\right) \cup\right.$ $i)=h\left(I\left(R_{N}^{\prime}\right)\right)\left(N^{x}\left(R_{N}^{\prime}\right)\right)=\Phi_{x}\left(R_{N}^{\prime}\right)$. This implies $\Phi_{y}\left(R_{N}\right) \geq \Phi_{y}\left(R_{N}^{\prime}\right)$. (iii) If $\tau\left(R_{i}\right)=x$ and $\tau\left(R_{i}^{\prime}\right)=\{x, y\}$, then, since $N^{x}\left(R_{N}\right) \supseteq N^{x}\left(R_{i}^{\prime}, R_{-i}\right)$, by monotonicity of $h$ we have $\Phi_{x}\left(R_{N}\right)=$ $h\left(I\left(R_{N}\right)\right)\left(N^{x}\left(R_{N}\right)\right) \geq h\left(I\left(R_{N}^{\prime}\right)\right)\left(N^{x}\left(R_{N}^{\prime}\right)\right)=\Phi_{x}\left(R_{N}^{\prime}\right)$. (iv) Finally, if $\tau\left(R_{i}\right)=y$ and $\tau\left(R_{i}^{\prime}\right)=\{x, y\}$, then, again by monotonicity of $h, \Phi_{x}\left(R_{N}\right)=h\left(I\left(R_{N}\right)\right)\left(N^{x}\left(R_{N}\right)\right) \leq h\left(I\left(R_{N}^{\prime}\right)\right)\left(N^{x}\left(R_{N}^{\prime}\right)\right)=\Phi_{x}\left(R_{N}^{\prime}\right)$, which implies $\Phi_{y}\left(R^{\prime} N\right) \leq \Phi_{y}\left(R_{N}\right)$. This completes the proof that $\Phi$ is strategy-proof.

For the only if part, consider a unanimous and strategy-proof probabilistic social choice function $\Phi$ on $\mathcal{D}^{n}$. Then $\Phi_{\{x, y\}}\left(R_{N}\right)=1$ for all $R_{N} \in \mathcal{D}^{n}$ by (the modified version of) Theorem 3.3. We show that $\Phi$ is a probabilistic generalized voting by committee rule. By strategy-proofness, $\Phi\left(R_{N}\right)=\Phi\left(Q_{N}\right)$ for all $R_{N}, Q_{N}$ with $I\left(R_{N}\right)=I\left(Q_{N}\right)$ and $N^{x}\left(R_{N}\right)=N^{x}\left(Q_{N}\right)$. Therefore, we can define $h(I)(C)=\Phi_{x}\left(R_{N}\right)$ if $I=I\left(R_{N}\right)$ and $N^{x}\left(R_{N}\right)=C$, for all $I \in \mathcal{P}(N) \backslash\{N\}$ and $C \subseteq N \backslash I$.

By unanimity of $\Phi, h(I)(\emptyset)=0$ and $h(I)(N \backslash I)=1$, and by strategy-proofness, $h(I)(C) \leq$ $h(I)\left(C^{\prime}\right)$ for all $I \in \mathcal{P} \backslash\{N\}$ and all $C, C^{\prime} \in \mathcal{P}(N \backslash I)$ with $C \subseteq C^{\prime}$.

It is left to prove that $h$ is monotonic. Let $I \in \mathcal{P}(N) \backslash\{N\}, C \in \mathcal{P}(N \backslash I), i \in C, I^{\prime}=I \cup i$. Let $Q_{N} \in \mathcal{D}^{n}$ such that $I\left(Q_{N}\right)=I$ and $N^{x}\left(Q_{N}\right)=C \backslash i$, and let $V_{N} \in \mathcal{D}^{n}$ such that $I\left(V_{N}\right)=I \cup i=I^{\prime}$ and $N^{x}\left(V_{N}\right)=C \backslash i$. Then by strategy-proofness, $\Phi_{x}\left(Q_{N}\right) \leq \Phi_{x}\left(V_{N}\right)$, otherwise $i$ manipulates at $Q_{N}$ via $V_{i}$. Hence $h(I)(C \backslash i) \leq h\left(I^{\prime}\right)(C \backslash i)$, which is the first inequality in the definition of monotonicity. To prove the second inequality, consider a profile $R_{N} \in \mathcal{D}^{n}$ such that $I\left(R_{N}\right)=I$ and 
$N^{x}\left(R_{N}\right)=C$. By strategy-proofness, $\Phi_{x}\left(R_{N}\right) \geq \Phi_{x}\left(V_{N}\right)$, otherwise agent $i$ manipulates at $R_{N}$ via $V_{i}$. Hence $h\left(I^{\prime}\right)(C \backslash i) \leq h(I)(C)$.

It is not clear if an analogon of Theorem 3.1 holds for the case of infinitely many alternatives, and whether a binary support domain is a deterministic extreme point domain. This would require a different proof which we leave for future research.

\section{Conclusion}

In this paper we have shown that every strategy-proof and unanimous PSCF on a binary restricted domain has binary support. We have shown that every such PSCF is a convex combination of strategy-proof and unanimous deterministic rules on that domain. We have characterized the latter rules as generalized voting by committee rules. We have also applied these results to some wellknown binary restricted domains like the single-dipped domain, the adjacent single-peaked domain, and the single-crossing domain with two tops. Finally, we have extended the characterization of strategy-proof and unanimous PSCFs on a binary restricted domain to the case of infinitely many alternatives.

\section{References}

Barberà S, Berga D, Moreno B (2012) Domains, ranges and strategy-proofness: the case of singledipped preferences. Social Choice and Welfare 39:335-352

Chatterji S, Roy S, Sen A (2012) The structure of strategy-proof random social choice functions over product domains and lexicographically separable preferences. Journal of Mathematical Economics 48:353-366

Chatterji S, Sen A, Zeng H (2014) Random dictatorship domains. Games and Economic Behavior $86: 212-236$

Gibbard A (1977) Manipulation of schemes that mix voting with chance. Econometrica 45:665-681

Manjunath V (2014) Efficient and strategy-proof social choice when preferences are single-dipped. International Journal of Game Theory 43:579-597

Peremans W, Storcken T (1999) Strategy-proofness on single-dipped preference domains. In de Swart HMC (ed.) Logic, Game theory and Social choice. Tilburg University Press, The Netherlands

Peters H, Roy S, Sen A, Storcken T (2014) Probabilistic strategy-proof rules over single-peaked domains. Journal of Mathematical Economics 52:123-127

Rockafellar RT (1970) Convex analysis. Princeton University Press, Princeton NJ

Sen A (2011) The Gibbard random dictatorship theorem: a generalization and a new proof. SERIEs Journal of the Spanish Economic Association 2:515-527 